\title{
Effectiveness of a 12-Week Program of Active and Passive Stretching in Improving Low Back and Neck Pain in Japanese Sedentary Men
}

\author{
Yuna Naraoka $^{1,2}$, Mikiyuki Katagiri' ${ }^{1}$, Takuji Shirasawa ${ }^{1}$ \\ ${ }^{1}$ Shirasawa Anti-Aging Medical Institute, Tokyo, Japan \\ ${ }^{2}$ Japanese Center for Research on Woman in Sport, Juntendo University, Tokyo, Japan \\ Email: ynaraoka@juntendo.ac.jp
}

How to cite this paper: Naraoka, Y., Katagiri, M. and Shirasawa, T. (2017) Effectiveness of a 12-Week Program of Active and Passive Stretching in Improving Low Back and Neck Pain in Japanese Sedentary Men. Health, 9, 493-505.

https://doi.org/10.4236/health.2017.93035

Received: February 8, 2017

Accepted: March 21, 2017

Published: March 24, 2017

Copyright ( 2017 by authors and Scientific Research Publishing Inc. This work is licensed under the Creative Commons Attribution International License (CC BY 4.0).

http://creativecommons.org/licenses/by/4.0/

(c) (i) Open Access

\begin{abstract}
Purpose: Muscle stretching is frequently prescribed in physical therapy to manage lower back and neck pain. However, there is no clear evidence regarding the differences in effectiveness of active and passive stretching. Therefore, we aimed to evaluate the relative effectiveness of a 12-week program of active and passive stretching on selected physical and mental stress variables of sedentary men with lower back and neck pain. Methods: A cohort of 28 sedentary men, 30 - 49 years old, were divided into two intervention groups: the passive stretching group (PSG, $\mathrm{n}=15$ ) and the active stretching group (ASG, $\mathrm{n}$ =13). A trainer assisted with static passive stretching, while participants in the ASG were provided with an instructional video. The following outcomes were measured at the start and end of the first and twelfth week of the stretching program: physical measures (visual analogue scale score of lower back and neck pain; finger-to-floor distance, gravimetric assessment of pelvic tilt, muscle hardness of the biceps femoris, and straight-leg raising) and mental stress measures ( $\alpha$-amylase and cortisol levels in saliva samples). Results: Although both active and passive stretching produced acute changes in lower back and neck pain, only passive stretching yielded long-term improvement in pain, finger-to-floor distance, pelvic tilt, hardness of biceps femoris muscle and cortisol levels $(\mathrm{p}<$ 0.01). Conclusion: Passive stretching is superior to active stretching in reducing pain, increasing muscle extensibility and correcting posture among a group of sedentary men with lower back and neck pain.
\end{abstract}

\section{Keywords}

Active Stretching, Passive Stretching, Lower Back Pain, Neck Pain

\section{Introduction}

Lower back pain is prevalent in adults, with approximately $80 \%-90 \%$ of adults 
having either previously experienced or being currently experiencing lower back pain. In fact, $80 \%$ of adults will experience lower back pain at least once in their lifetime [1]. Lower back pain is also prevalent in children, especially among pediatric athletes [2] [3] [4]. Although a causal factor can be identified in 5\% - 15\% of cases, more than $85 \%$ of patients have nonspecific lower back pain [5]. Several studies have identified smoking, high body mass index (BMI), and tight quadriceps and hamstring muscles as specific risk factors for lower back pain [6] [7]. Among these factors, hamstring tightness has been shown to highly correlate to lower back pain [8] [9] [10]. Due to the hamstring muscles attaching to the pelvis and the knee, crossing the hip posteriorly, decreased extensibility of the hamstrings will negatively influence hip and pelvis motion. Yet, evidence linking shortened hamstrings to lower back pain remains insufficient.

Neck pain is also a major somatic complaint among Japanese adults. Neck pain is defined as discomfort or dull pain caused by muscle stiffness around the back of the head and through the shoulder and/or scapular region [11]. Again, in many cases, chronic neck pain is non-specific [12]. Neck pain can be aggravated by a number of factors, including: cervical spine disease, glenohumeral joint disease, cardiovascular disease, eye fatigue, and temporomandibular arthrosis [13] [14]. Moreover, in many patients, neck pain coexists with lower back pain and negatively influences health-related quality of life (QOL) [15].

Several various treatment approaches for lower back and neck pain have been proposed and evaluated. Among those, the use of passive stretching to alleviate symptoms of lower back and neck pain has been gaining popularity. Two modes of stretching are prescribed, static and dynamic stretching, each having a distinct effect on the muscle. Dynamic stretching aims to increase heart rate and muscle temperature and incorporates movements that mimic a specific sport or exercise in an exaggerated yet controlled manner; often included during the warm-up or in preparation for a sports event, whereas static stretching aims to relax the muscle and increase its extensibility. Static stretching can be further subdivided as follows: active stretching aims to induce relaxation of the contractile tissues of a muscle, via reflex inhibition, through contraction of the opposing (antagonist) muscle, while passive stretching aims to increase the extensibility of the non-contractile tissues of muscle (fascia and neurovascular tissue) by application of sustained, continuous stretch without contraction. Currently, evidence regarding the differences in the therapeutic effects of these different modes of stretching, remains controversial [16]-[22]. Therefore, the aim of our study was to evaluate the relative effectiveness of a 12-week program of active and passive stretching on selected physical and mental stress variables of sedentary men with lower back and neck pain. Activities for both modes of stretching were designed by the Fubic Company, Ltd (Tokyo, Japan), as part of their core balance stretching program.

\section{Material and Methods}

\subsection{Participants}

We undertook an observational study to evaluate outcomes for passive and ac- 
tive stretching programs among sedentary men, aged 30 to 49 years, who have desk jobs and complain of lower back and neck pain with an intensity $\geq 30 \mathrm{~mm}$ on a $100 \mathrm{~mm}$ visual analogue scale (VAS) of pain. Prospective participants were recruited through advertisements on the Edihas Co. Ltd. web site at and screened to exclude individuals who were regularly physically active, those with specific contraindications to stretching, routinely used pharmaceutical drugs (such as nonsteroidal anti-inflammatory drugs, that could modify measured study outcomes), poor lifestyle habits (including eating disorders, alcohol dependence, night shift work, and irregular holidays), those who have had participated in other clinical investigations within the month prior to our study, and those who were deemed to be unsuitable per their doctor's discretion. Following this screening procedure, 32 men who met our eligibility criteria and provided informed consent were included in the study. In this research, we focused on sedentary male subjects aged from 30 to 49 who were prone to suffer from mental stress wedged between bosses and subordinates. Moreover, in order to avoid changes in physical condition due to female hormones, we adopted only male subjects. We calculated sample size using PS: Power and Sample Size Calculation. Our study protocol was approved by the Shirasawa Clinical Trial Center Ethical Review Board and was conducted in accordance to the principles of the amended Declaration of Helsinki. This study carried out from September to December in 2015 at Fubic Company Tokyo, Japan.

\subsection{Study Design}

Participants were allocated to two intervention groups, ensuring an equal distribution of age, height, weight, body mass index (BMI), and VAS scores between the groups: the passive stretching group (PSG) $(n=16)$ and the active stretching group (ASG) $(\mathrm{n}=16)$. Both groups completed a 12 -week program of either passive or active stretching. Stretching activities were performed on a daily basis after work, between 18:00 - 21:00, requiring about 40 minutes to complete. All stretching activities were provided by the Fubic Company as part of their core balance stretching program. For participants in the PSG, passive stretching of the quadriceps femoris, hamstring muscles, iliopsoas, trapezius, and pectoralis major were performed by a qualified trainer from the Fubic Company. Participants in the ASG were shown an instructional video for stretching of the quadriceps femoris, hamstring muscles, iliopsoas, trapezius, and pectoralis major.

The following baseline measurements were obtained prior to the start of the stretching program: height, BMI, finger-floor distance (FFD), hardness of the biceps femoris muscle bilaterally, angle of straight leg raising (SLR), the VAS lower back and neck pain score, the gravimetric test of the position of the body center of gravity (COG) relative to the gravitational vector, and levels of $\alpha$-amylase and cortisol from saliva samples.

\subsection{Pain Assessment}

To assess pain, a 100 mm VAS was used, with anchors at "0" (no pain) and "100" 
(worse pain possible). Participants were asked to draw a vertical line through the horizontal VAS line at the point which best represented the intensity of their pain, before and after stretching.

\subsection{FFD Assessment}

FFD was measured to assess the flexibility of the hamstrings and the muscles of the lumbosacral region. To obtain FFD data, participants were asked to flex forward, keeping both knee joints in extension, and then measuring the distance between the fingertips and the floor both before and after stretching. Touching of the fingertips to the floor was scored as " 0 ". The measured values were defined as "plus" for below the floor and as a "minus" above the floor. Care was taken to ensure that flexion was contributed principally through flexion of the lumbar spine.

\subsection{SLR Assessment}

The angle of SLR, which measures the global flexibility of the hamstring and extensor muscles of the lumbosacral spine, were measured by passively moving the hip into flexion, maintaining the knee in extension. The angle formed by the thigh, relative to horizontal, was measured using a hand-held goniometer (MEF Surgetec Co., Ltd.).

\subsection{Gravimetric Assessment}

For the gravimetric test, participants stood with on a gravimetric platform for 30 seconds, with their eyes open. Projection of the COG on the platform, relative to the gravitational vector, was measured according to the manufacturer's instructions using Gravicoda (GP-31, ANIMA Corp.).

\subsection{Analysis of Saliva Samples}

Saliva was collected using a salivette (SARSTEDT TA \& CO). Samples were immediately stored in a cooler and frozen until analysis. The $\alpha$-amylase and cortisol content were measured by the Yanaihara Institute Inc. (Shizuoka, Japan). These levels were used as a surrogate measure of the patient's mental stress level.

\subsection{Measurement of Muscle Hardness (Elasticity)}

Muscle hardness was quantified for both the right and left biceps femoris muscle in prone, using the Muscle Hardness Meter (Imoto Machinery Company, LTD.).

\subsection{Data Analysis}

With the exception of height and BMI, all other variables were measured at baseline (start of the first week of stretching, $1 \mathrm{~W}$-pre), at the end of the first week of stretching (1W-post), the start of the 12th week of stretching (12W-pre), and the end of the 12th week of stretching (12W-post). Descriptive statistics, namely the mean (standard deviation, SD), were computed for each outcome variable: VAS, FFD, gravimetric test, SLR, muscle hardness and saliva $\alpha$-amylase and cortisol 
content. Between-group differences at each time point of measurement were evaluated using a Mann-Whitney-U test. Within-group changes at each time point of measurement from baseline was evaluated using the Wilcoxon test. As deemed adequate, the confidence interval of the mean was calculated. All analyses were performed using SPSS (version 20.0; SPSS, IBM), with statistical significance set at $\mathrm{p}<0.01$.

\section{Results}

The physical characteristics of our study group are presented in Table 1, with relevant baseline characteristics summarized as followed: age 39.0 (4.7) years; height, 173.7 (5.1) cm; body weight, 70.1 (8.9) kg; and heart rate, 82.3 (14.4) bpm in the PSG at the age of 40.54 (6.2) years; height, $172.91(5.9) \mathrm{cm}$; body weight, 71.32 (12.6) kg; and heart rate, 79.46 (14.4) bpm in the ASG. Of the 32 participants initially entered in the study, 4 failed to complete the evaluation at the 12 -week time point and their data were subsequently excluded from the analysis.

\subsection{Pain Assessment}

The change in VAS scores for lower back and neck pain is reported in Figure 1 (a) and b respectively. With regards to lower back pain, a significant decrease in VAS for the PSG was identified from: $1 \mathrm{~W}$-pre to $1 \mathrm{~W}$-post $(\mathrm{p}<0.001)$; $1 \mathrm{~W}$-pre to $12 \mathrm{~W}$-pre $(\mathrm{p}<0.001)$; and $12 \mathrm{~W}$-pre to $12 \mathrm{~W}$-post $(\mathrm{p}<0.001)$. For the ASG, the following change in VAS scores was identified: $1 \mathrm{~W}$-pre to $1 \mathrm{~W}$-post $(\mathrm{p}=0.007)$ and $12 \mathrm{~W}$-pre to $12 \mathrm{~W}$-post $(\mathrm{p}<0.001)$. Therefore, although both passive and active stretching decreased lower back pain immediately after stretching, only passive stretching yielded long-term effects (i.e., decrease from $1 \mathrm{~W}$-pre to $12 \mathrm{~W}$-pre). Comparing PSG to ASG, VAS score of lower back pain in PSG was significantly lower than that of ASG in $12 \mathrm{~W}$-pre $(\mathrm{p}=0.036)$ and $12 \mathrm{~W}$-post $(\mathrm{p}=0.005)$.

In regards to neck pain in the PSG (Figure $1(\mathrm{~b})$ ), VAS scores were significantly lower at $1 \mathrm{~W}$-post, $12 \mathrm{~W}$-pre and $12 \mathrm{~W}$-post, relative to $1 \mathrm{~W}$-pre $(\mathrm{p}<0.001)$. By comparison, for the ASG, VAS scores decreased from $1 \mathrm{~W}$-pre to $1 \mathrm{~W}$ post ( $\mathrm{p}=$ 0.004 ) and $12 \mathrm{~W}$-pre to $12 \mathrm{~W}$-post $(\mathrm{p}<0.001)$. Compared PSG to ASG, VAS score

Table 1. Baseline characteristics of participants in the passive stretching group (PSG, $\mathrm{n}=$ 15) and active stretching group (ASG, $\mathrm{n}=13$ ).

\begin{tabular}{cccc}
\hline & & PSG $(\mathrm{n}=15)$ & ASG $(\mathrm{n}=13)$ \\
\cline { 2 - 4 } & & Mean $(\mathrm{SD})$ & Mean $(\mathrm{SD})$ \\
\hline Age & years & $39.00(4.71)$ & $40.54(6.24)$ \\
height & $\mathrm{cm}$ & $173.71(5.14)$ & $172.91(5.92)$ \\
weight & $\mathrm{kg}$ & $70.11(8.92)$ & $71.32(12.57)$ \\
BMI & $\mathrm{kg} / \mathrm{m}^{2}$ & $23.24(2.68)$ & $24.29(3.57)$ \\
systolic blood pressure & $\mathrm{mmHg}$ & $126.67(22.30)$ & $119.62(15.39)$ \\
diastolic blood pressure & $\mathrm{mmHg}$ & $83.20(16.65)$ & $78.54(16.23)$ \\
heart rate & beats $/ \mathrm{min}$ & $82.27(14.39)$ & $79.46(14.43)$ \\
\hline
\end{tabular}

Notes: BMI, body mass index. PSG, passive-stretching-group. ASG, active stretching group. 

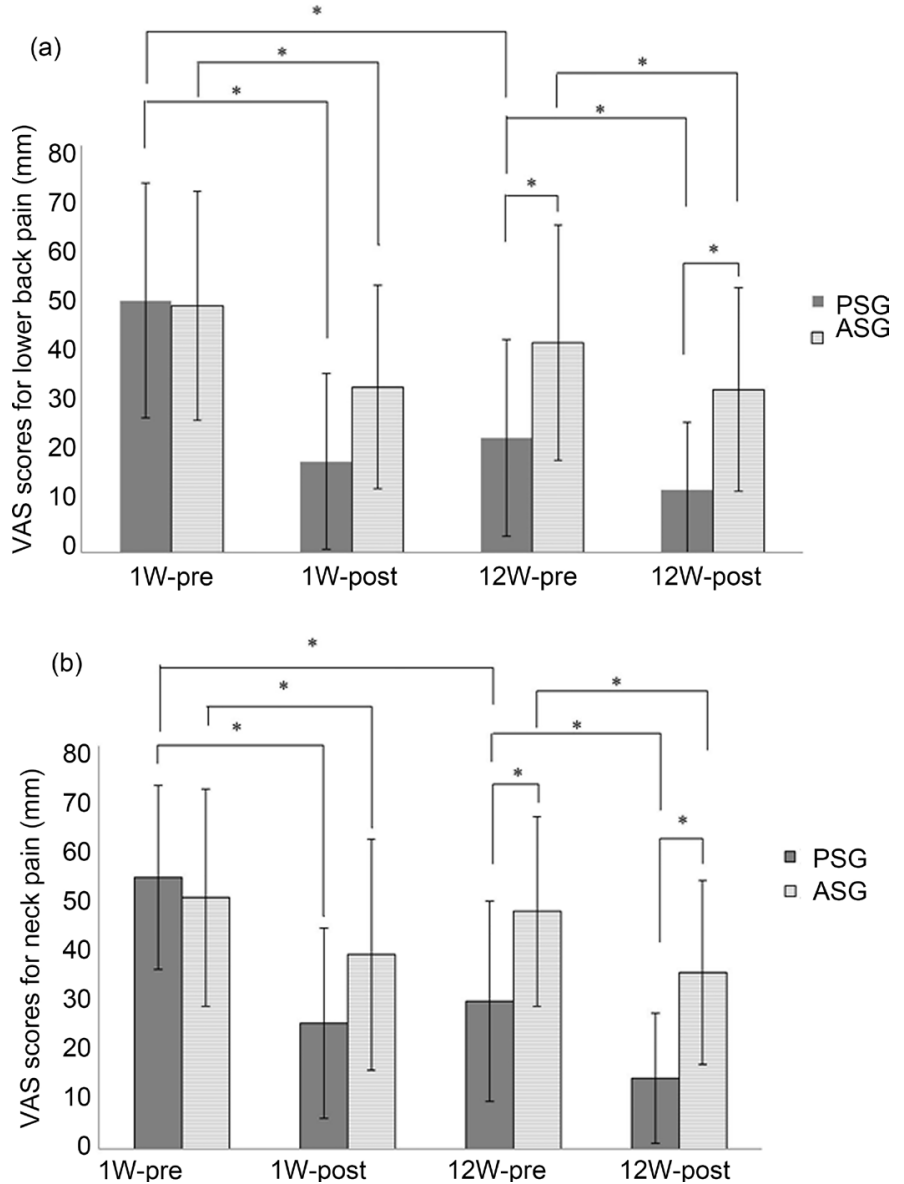

Figure 1. Comparison of VAS scores for subjects in the PSG and ASG regarding lower back pain (a) and neck pain (b). Measurment of pre-stretching in 1st week, 1W-pre; Measurement of post stretching in 1st week, $1 \mathrm{~W}$-post; Measurment of pre stretching in 12nd week, $12 \mathrm{~W}$-pre; Measurement of post stretching in $12 \mathrm{nd}$ week, $12 \mathrm{~W}$-post.

of neck pain in PSG was significantly lower than that of ASG in $12 \mathrm{~W}$-pre ( $\mathrm{p}=$ $0.023)$ and $12 \mathrm{~W}$-post $(\mathrm{p}=0.004)$.

\subsection{FFD Assessment}

The change in FFD is reported in Figure 2 for the PSG, FFD increased, relative to $1 \mathrm{~W}$-pre, at $1 \mathrm{~W}$-post $(\mathrm{p}<0.001), 12 \mathrm{~W}$-pre $(\mathrm{p}<0.001)$ and $12 \mathrm{~W}$-post $(\mathrm{p}<0.001)$. By comparison, for the ASG, FFD increased only from $1 \mathrm{~W}$-pre to $1 \mathrm{~W}$-post ( $\mathrm{p}=$ 0.008). Comparing PSG to ASG, although there was a trend toward the high variant of FFD in PSG at every point, no significant difference was found.

\subsection{SLR Assessment}

There was no effect of either stretching program on the SLR.

\subsection{Measurement of Muscle Hardness}

In the PSG, hardness of the biceps femoris muscle decreased bilaterally, at $12 \mathrm{~W}$ pre compared to $1 \mathrm{~W}$-pre $(\mathrm{p}<0.001)$, a long-term effect of static stretching on the hardness of the biceps femoris was indicative. Any effect of stretching on the hard- 


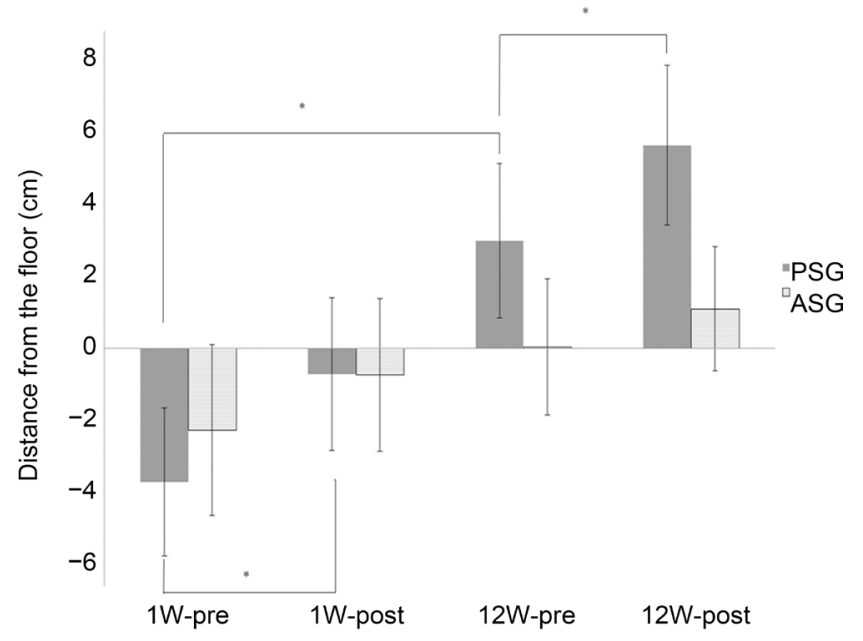

Figure 2. Comparison of FFD scores for subject PSG and ASG.

ness of the biceps femoris was not identified at other time points of measurementfor the PSG and ASG.

\subsection{Gravimetric Assessment}

The analysis of the position of the COG for the ASG and PSG is shown in Figure 3. For analysis, participants within each group were classified into an anteriorCOG group and a posterior-COG group, based on the median value of the COG position within each group: PSG, $-1.54 \mathrm{~cm}$; and ASG, $-3.25 \mathrm{~cm}$. Based on this classification scheme, 8 participants in the PSG and 6 in the ASG were identified has having an anterior-COG position, with 7 participants in the PSG and 7 in the ASG identified has having a posterior-COG.

The change in COG position is reported in Table 2. For the PSG, although the position of the COG was significantly different between the anterior-COG and posterior-COG subgroup at $1 \mathrm{~W}$-pre $(\mathrm{p}=0.001)$ and $12 \mathrm{~W}$-pre $(\mathrm{p}=0.009)$, there were no significant between-group differences at $1 \mathrm{~W}$-post and $12 \mathrm{~W}$-post. Therefore, static stretching produced a significant effect on COG position, of equal magnitude between the anterior- and posterior-COG groups. In contrast, significant differences between the COG position subgroups were identified in the ASG at $1 \mathrm{~W}$-pre $(\mathrm{p}=0.003), 1 \mathrm{~W}$-post $(\mathrm{p}=0.001)$ and $12 \mathrm{~W}$-pre $(\mathrm{p}=0.002)$, with no effect of active stretching the position of the COG. These results suggest that passive stretch have effects to adjust the COG.

\subsection{Analysis of Saliva Samples}

In the PSG, a significant change in cortisol levels, shown in Table 3, were identified from $1 \mathrm{~W}$-pre to $1 \mathrm{~W}$-post $(\mathrm{p}=0.006)$ and $12 \mathrm{~W}$-pre to $12 \mathrm{~W}$-post $(\mathrm{p}=0.008)$. No differences in cortisol levels were identified in the ASG. Neither stretching program had an effect on $\alpha$-amylase levels.

\section{Discussion}

In this study, our aim was to evaluate and compare the relative effects of a12-week 
(a)
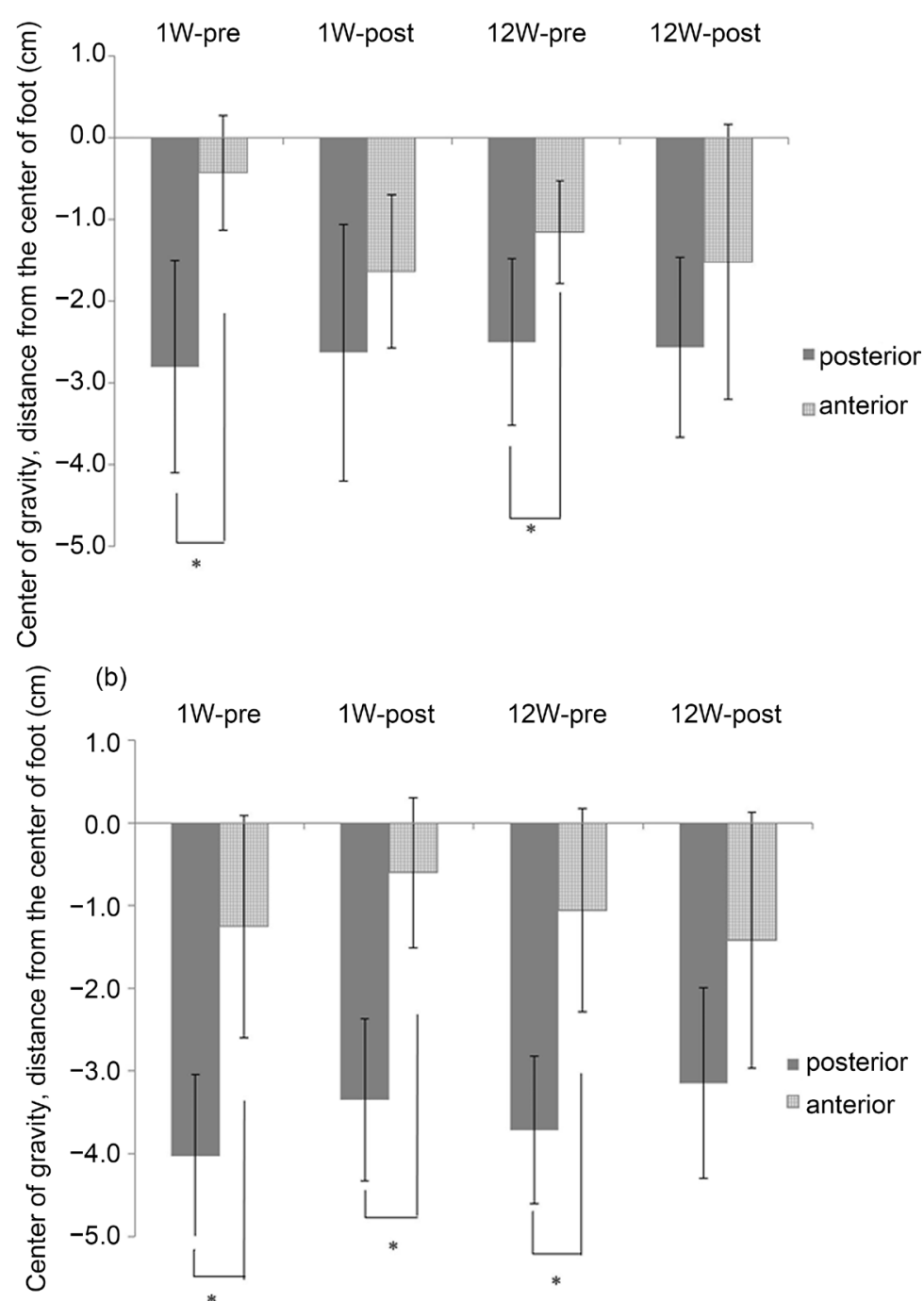

Figure 3. Comparison of gravimetric test for subjects posterior-gravity-group and anterior-gravity-group within PSG (a) and ASG (b). Center of the foot was scored as "0". The measured values were defined the as "plus" for posterior and as "minus" anterior in center of the foot. Participants within each group were classified into an anterior-COG group and a posterior-COG group, based on the median value of the COG position within each group.

Table 2. Within- and between-group evaluation of gravimetric tests.

\begin{tabular}{ccccc}
\hline & 1W-pre & 1W-post & 12W-pre & 12W-post \\
\cline { 2 - 5 } & Mean (SD) & Mean (SD) & Mean (SD) & Mean (SD) \\
\hline PSG & & & & \\
posterior-gravity (cm) & $-2.80(1.30)$ & $-2.63(1.57)$ & $-2.50(1.02)$ & $-2.57(1.10)$ \\
anterior-gravity (cm) & $-0.43(0.70)$ & $-1.64(0.94)$ & $-1.15(0.63)$ & $-1.52(1.68)$ \\
p (posterior vs. anterior) & $0.011^{*}$ & 0.323 & $0.021^{*}$ & 0.298 \\
ASG & & & & $-3.15(1.15)$ \\
posterior-gravity (cm) & $-4.03(0.99)$ & $-3.35(0.98)$ & $-3.72(0.89)$ & $-1.42(1.55)$ \\
anterior-gravity (cm) & $-1.25(1.35)$ & $-0.60(0.91)$ & $-1.06(1.23)$ & -1.0072 \\
p (posterior vs. anterior) & $0.007^{*}$ & $0.007^{*}$ & $0.007^{*}$ & 0.042 \\
\hline
\end{tabular}


Table 3. Within-group analysis of measured outcomes (VAS, saliva content, FFD, muscle hardness, SLR, and gravimetric test) for the passive stretching (PSG) and active stretching (ASG) groups.

\begin{tabular}{|c|c|c|c|c|c|c|c|}
\hline & $\begin{array}{r}1 \mathrm{~W} \text {-pre } \\
\text { Mean (SD) }\end{array}$ & $\begin{array}{c}\text { 1W-post } \\
\text { Mean (SD) vs }\end{array}$ & $\begin{array}{c}\mathrm{p} \\
\text { s. } 1 \mathrm{~W} \text {-pre }\end{array}$ & $\begin{array}{l}\text { 12W-pre } \\
\text { Mean (SD) }\end{array}$ & $\begin{array}{c}\mathrm{p} \\
\text { vs. } 1 \mathrm{~W} \text {-pre }\end{array}$ & $\begin{array}{l}\text { 12W-post } \\
\text { Mean (SD) v }\end{array}$ & $\begin{array}{c}\mathrm{p} \\
\text { vs. } 12 \mathrm{~W}-\mathrm{pre}\end{array}$ \\
\hline \multicolumn{8}{|l|}{ PSG $(n=15)$} \\
\hline $\begin{array}{l}\text { Neck pain } \\
(\mathrm{mm})\end{array}$ & $53.93(18.30)$ & $24.97(18.87)$ & $<0.001^{\star}$ & $29.30(19.88)$ & $<0.001^{\star}$ & $14.00(12.89)$ & $<0.001^{\star}$ \\
\hline $\begin{array}{l}\text { Lower back pain } \\
\qquad(\mathrm{mm})\end{array}$ & $49.50(23.10)$ & $17.87(17.26)$ & $<0.001^{\star}$ & $22.49(19.37)$ & $<0.001^{*}$ & $12.27(13.36)$ & $<0.001^{*}$ \\
\hline $\begin{array}{l}\text { Cortisol } \\
(\mu \mathrm{g} / \mathrm{dL})\end{array}$ & $0.13(0.06)$ & $0.08(0.03)$ & $0.006^{*}$ & $0.14(0.10)$ & 0.760 & $0.08(0.05)$ & 0.008 \\
\hline $\begin{array}{l}\alpha \text {-amylase } \\
(\mathrm{U} / \mathrm{mL})\end{array}$ & $382.82(222.67)$ & $248.34(145.08)$ & 0.016 & $340.25(251.14)$ & 0.360 & $238.10(195.18)$ & 0.014 \\
\hline $\begin{array}{l}\text { Finger floor distance (FFD) } \\
\qquad(\mathrm{cm})\end{array}$ & $-3.38(7.24)$ & $-0.65(7.45)$ & $<0.001^{\star}$ & $2.71(7.56)$ & $<0.001^{\star}$ & $5.12(7.82)$ & $<0.001^{\star}$ \\
\hline $\begin{array}{c}\text { Hardness (left-biceps femoris) } \\
-\end{array}$ & $58.73(4.24)$ & $57.13(4.80)$ & 0.016 & $52.83(2.76)$ & $<0.001^{*}$ & $53.70(3.30)$ & 0.714 \\
\hline $\begin{array}{c}\text { Hardness (right-biceps femoris) } \\
-\end{array}$ & $58.67(3.56)$ & $58.80(3.86)$ & 0.344 & $51.10(2.98)$ & $<0.001^{*}$ & $51.77(2.76)$ & 0.247 \\
\hline $\begin{array}{c}\text { SLR (left side) } \\
\left({ }^{\circ}\right)\end{array}$ & $61.60(9.44)$ & $62.27(8.57)$ & 0.895 & $58.47(6.12)$ & 0.329 & $60.33(5.33)$ & 0.300 \\
\hline $\begin{array}{l}\text { SLR (right side) } \\
\left({ }^{\circ}\right)\end{array}$ & $60.60(9.06)$ & $62.67(8.48)$ & 0.382 & $62.33(1.74)$ & 0.614 & $66.27(4.30)$ & 0.043 \\
\hline \multicolumn{8}{|l|}{ Garavimetric test } \\
\hline $\begin{array}{l}\text { Dimension } \\
\left(\mathrm{cm}^{2}\right)\end{array}$ & $1.60(0.94)$ & $1.77(1.37)$ & 0.480 & $1.89(0.87)$ & 0.340 & $2.01(0.99)$ & 0.144 \\
\hline $\begin{array}{l}\text { Right-left } \\
\quad(\mathrm{cm})\end{array}$ & $-0.33(0.75)$ & $-0.30(0.80)$ & 0.670 & $-0.11(0.62)$ & 0.385 & $-0.46(0.86)$ & 0.113 \\
\hline $\begin{array}{l}\text { Anterior-posterior } \\
(\mathrm{cm})\end{array}$ & $-1.70(1.60)$ & $-2.17(1.37)$ & 0.859 & $-1.87(1.08)$ & 0.504 & $-2.08(1.45)$ & 0.493 \\
\hline \multicolumn{8}{|l|}{ ASG $(n=13)$} \\
\hline $\begin{array}{l}\text { Neck pain } \\
\quad(\mathrm{mm})\end{array}$ & 49.85 (20.89) & $38.62(22.07)$ & 0.004 & $47.12(18.85)$ & 0.639 & $35.03(18.26)$ & $<0.001^{*}$ \\
\hline $\begin{array}{l}\text { Lower back pain } \\
\qquad(\mathrm{mm})\end{array}$ & $48.50(20.66)$ & 32.54 (19.47) & 0.007 & $41.18(23.14)$ & 0.303 & 32.01 (19.99) & $<0.001^{*}$ \\
\hline $\begin{array}{l}\text { Cortisol } \\
(\mu \mathrm{g} / \mathrm{dL})\end{array}$ & $0.15(0.11)$ & $0.10(0.06)$ & 0.053 & $0.13(0.06)$ & 0.610 & $0.10(0.04)$ & 0.059 \\
\hline $\begin{array}{l}\alpha \text {-amylase } \\
(\mathrm{U} / \mathrm{mL})\end{array}$ & $384.11(265.54)$ & $282.43(138.07)$ & 0.145 & $276.10(136.42)$ & 0.050 & $258.36(131.75)$ & 0.540 \\
\hline $\begin{array}{l}\text { Finger floor distance (FFD) } \\
\qquad(\mathrm{cm})\end{array}$ & $-2.06(7.15)$ & $-0.67(6.39)$ & 0.008 & $0.04(5.07)$ & 0.066 & $1.00(5.19)$ & 0.044 \\
\hline $\begin{array}{c}\text { Hardness (left-biceps femoris) } \\
-\end{array}$ & $58.46(4.85)$ & $57.85(4.21)$ & 0.621 & 54.27 (3.39) & 0.053 & $54.23(2.11)$ & 0.270 \\
\hline $\begin{array}{c}\text { Hardness (right-biceps femoris) } \\
-\end{array}$ & $58.92(4.84)$ & $58.62(4.51)$ & 0.973 & $53.19(3.82)$ & 0.010 & $52.81(2.74)$ & 0.575 \\
\hline $\begin{array}{c}\text { SLR (left side) } \\
\left({ }^{\circ}\right)\end{array}$ & 61.46 (10.59) & $67.85(18.84)$ & 0.755 & $61.46(8.03)$ & 1.000 & $62.31(6.94)$ & 0.248 \\
\hline $\begin{array}{l}\text { SLR (right side) } \\
\left({ }^{\circ}\right)\end{array}$ & $63.85(10.86)$ & 69.54 (18.89) & 0.682 & $64.62(8.07)$ & 0.749 & $68.08(8.26)$ & 0.226 \\
\hline \multicolumn{8}{|l|}{ Garavimetric test } \\
\hline $\begin{array}{l}\text { Dimension } \\
\qquad\left(\mathrm{cm}^{2}\right)\end{array}$ & $1.81(0.88)$ & $1.75(0.87)$ & 0.869 & $1.81(0.87)$ & 0.476 & $\begin{array}{c}1.68(1.62) \\
-\end{array}$ & 0.992 \\
\hline $\begin{array}{l}\text { Right-left } \\
\quad(\mathrm{cm})\end{array}$ & $-0.05(0.86)$ & $0.03(0.79)$ & 0.580 & $-0.07(0.70)$ & 0.143 & $0.22(1.81)$ & 0.927 \\
\hline $\begin{array}{l}\text { Anterior-posterior } \\
(\mathrm{cm})\end{array}$ & $-2.43(0.45)$ & $-1.99(0.37)$ & 0.676 & $-2.18(1.92)$ & 0.827 & $-2.12(1.62)$ & 0.380 \\
\hline
\end{tabular}

Notes: values are reported as the mean (SD); W, week; PSG, passive stretching group; ASG, active stretching group; SLR, Straight Leg Raise ${ }^{\star}, \mathrm{p}<0.01$. To compare with effects of stretching for short term and long term, p-value were calculated concerning $1 \mathrm{~W}$-pre and $1 \mathrm{~W}$-post, $12 \mathrm{~W}$-pre and $12 \mathrm{~W}$-post and $1 \mathrm{~W}$-pre and $12 \mathrm{~W}$-pre. 
program of active or passive stretching in relieving lower back and neck pain in a group of sedentary men, 30 to 49 years of age. Outcomes measures were evaluated both at the physical (VAS, SLR, muscle hardness, COG position) and mental stress (cortisol and $\alpha$-amylase levels) levels. Although both passive and active stretching improved lower back and neck pain, long-term benefits were only identified among participants who completed the passive stretching program (PSG). In addition, the FFD scores improved in parallel with VAS scores. Long-term improvement in VAS and FFD scores were identified only among participants in the PSG, indicative of the effectiveness of passive stretching in inducing long-term changes in muscle extensibility, compared to active stretching. An increase in FFD is indicative of improvement in hamstring extensibility [23], with improvement in hamstring length being associated with improvement of lower back pain. Hasebe et al. have previously reported that improving hamstrings length may reduce lower back pain [24], with our results being consistent with their conclusion. According to Fasen et al., a 4-week program of active stretching can effectively increase hamstring length, with 8 weeks of regular stretching yielding improvements, regardless of active or passive mode of stretching [25]. In contrast, Halbertsma et al. did not identify a beneficial effects of passive stretching, measured acutely either after a 10 -min bout of passive stretching or after a 4-week program of passive stretching [26].

Improvement in muscle length with passive stretching is contributed by a decrease in stiffness in non-contractile muscle tissue [19]. Based on our outcomes, we propose that a 12-week program of passive stretching is effective in improving the extensibility of connective tissue/nervous tissue, thereby improving muscle length.

A change in pelvic tilt position, resulting from an increased extensibility of the hamstring muscles, also contributed in our measured increase in flexibility (muscle length, SLR and FFD). Specifically, in the PSG, the 12-week program of static stretching was effective in correcting any excess in pelvic tilt position, due to hypoextensibility of muscles of the lumbosacral region, with no effect of active stretching being identified. We postulate that this correction in pelvic tilt would result from increased length not only of the hamstring muscles, but of other muscles of the lumbosacral region, including the quadriceps, iliopsoas, and tensor fasciae latae muscles in our study. As decreased mobility of the hip can increase the strain on spinal structures [27], improving hip mobility may be an important factor in decrease lower back pain. In fact, a positive association between the ratio of flexion of the lumbar region and the hip has been previously reported to directly influence lower back pain [28].

The risk factors for neck pain in sedentary workers include the lack of worksite support from colleagues and supervisors [14], insufficient sleep [29], and prolonged work and depression [30] [31]. Krantz et al. used surface electromyography to demonstrate the influence of mental and physical stress on the resting activity of the trapezius muscle [32] by providing evidence of the effectiveness in decreasing mental stress in improving neck pain. To estimate mental stress, we 
assessed cortisol levels in samples of saliva. Cortisol, which is the end of product of activity in the hypothalamic-pituitary-adrenal (HPA) axis, is an important stress hormone, which responds to short-term stress relieving activities. Since the level of cortisol significantly decreased only after passive stretching, we propose that static stretching provides some effect in relieving mental stress, likely through its direct influence in improving extensibility thereby improving range of motion and relieving neck pain.

The limitations of our study need to be considered in the interpretation of results. As we determined that change in pelvic position as an important factor in decreasing lower back pain, a specific measure of pelvic tilt using standard methods of hand-held goniometry is recommended over the more general gravimetric measures we used in our study. Moreover, the ASG did not receive direct supervision or assistance in performing the active stretching program and, therefore, it is not possible to determine if stretching activities were correctly performed.

\section{Conclusion}

In conclusion, although both passive and active stretching produced acute benefits of improved lower back and neck pain symptoms, including a decrease in VAS score, only passive stretching, performed with the assistance of a trainer, produced long-term effects and benefits in decreasing physical and mental indices of lower back and neck pain. Active stretching, using an instructional video, did not offer long-term therapeutic benefits among sedentary men, 30 - 49 years old, suffering from lower back and neck pain.

\section{Acknowledgements}

We thank all the participants and the professional staff of the Fubic Company, Ltd. This research was supported by Fubic CO., Ltd. The authors have no potential conflict of interests to declare.

\section{References}

[1] Cassidy, J.D., Carroll, L.J. and Côté, P. (1998) The Saskatchewan Health and Back Pain Survey. The Prevalence of Low Back Pain and Related Disability in Saskatchewan Adults. Spine, 23, 1860-1866.

[2] Deyo, R.A. (2002) Diagnostic Evaluation of LBP: Reaching a Specific Diagnosis Is Often Impossible. Archives of Internal Medicine, 162, 1444-1447.

https://doi.org/10.1001/archinte.162.13.1444

[3] Iwamoto, J., Abe, H., Tsukimura, Y. and Wakano, K. (2005) Relationship between Radiographic Abnormalities of Lumbar Spine and Incidence of Low Back Pain in High School Rugby Players: A Prospective Study. Scandinavian Journal of Medicine \& Science in Sports, 15, 163-168. https://doi.org/10.1111/j.1600-0838.2004.00414.x

[4] Sairyo, K., Katoh, S., Sakamaki, T., Komatsubara, S., Endo, K. and Yasui, N. (2003) Three Successive Stress Fractures at the Same Vertebral Level in an Adolescent Baseball Player. The American Journal of Sports Medicine, 31, 606-610.

[5] Deyo, R.A. and Weinstein, J.N. (2001) Low Back Pain. The New England Journal of Medicine, 344, 363-370. https://doi.org/10.1056/NEJM200102013440508 
[6] Feldman, D.E., Shrier, I., Rossignol, M. and Abenhaim, L. (2001) Risk Factors for the Development of Low Back Pain in Adolescence. American Journal of Epidemiology, 154, 30-36. https://doi.org/10.1093/aje/154.1.30

[7] Harreby, M., Nygaard, B., Jessen, T., et al. (1999) Risk Factors for Low Back Pain in a Cohort of 1389 Danish School Children: An Epidemiologic Study. European Spine Journal, 8, 444-450. https://doi.org/10.1007/s005860050203

[8] Porter, J.L. and Wilkinson, A. (1997) A Comparative Study between Asymptomatic and Chronic Low Back Pain in 18- to 36-Year-Old Men. Spine, 22, 1508-1513. https://doi.org/10.1097/00007632-199707010-00017

[9] Kottke, F.J., Pauley, D.L. and Ptak, R.A. (1966) The Rationale for Prolonged Stretching for Correction of Shortening of Connective Tissue. Archives of Physical Medicine and Rehabilitation, 47, 345-352.

[10] Mierau, D., Cassidy, J.D. and Yong-Hing, K. (1980) Low-Back Pain and Straight Leg Raising in Children and Adolescents. Spine, 14, 526-528. https://doi.org/10.1097/00007632-198905000-00010

[11] Yabuki, S. (2007) Pathogenesis of the Neck-Shoulder Stiffness. Clinics in Orthopedic Surgery, 42, 413-417. (In Japanese)

[12] McLean, S.M., May, S., Klaber-Moffett, J., Sharp, D.M. and Gardiner, E. (2010) Risk Factors for the Onset of Non-Specific Neck Pain: A Systematic Review. Journal of Epidemiology and Community Health, 64, 565-572.

https://doi.org/10.1136/jech.2009.090720

[13] Takagishi, K., Hoshino, Y. and Ide, J. (2008) A Project Study for Katakori, 20042006 (Commentary). Nihon Seikeigeka Gakkai Zasshi, 82, 901-911. (In Japanese)

[14] Fujii, T., Matsudaira, K., Noma, K., et al. (2012) Objective Measurement of NeckShoulder Discomfort and Analysis of Associated Factors. Rinsho Seikeigeka, 47, 619-624. (In Japanese)

[15] Kimura, T., Tsuda, Y., Uchida, S. and Eboshida, A. (2006) Association of Perceived Stress and Stiff Neck/Shoulder with Health Status: Multiple Regression Models by Gender. Hiroshima Journal of Medical Sciences, 55, 101-107.

[16] Ogston, J.B., Crowell, R.D. and Konowalchuk, B.K. (2016) Graded Group Exercise and Fear Avoidance Behavior Modification in the Treatment of Chronic Low Back Pain. Journal of Back and Musculoskeletal Rehabilitation, 29, 673-684. https://doi.org/10.3233/BMR-160669

[17] Ohtsuki, K. (2014) A 3-Month Follow-Up Study of the Long-Term Effects of Direct Stretching of the Tensor Fasciae Latae Muscle in Patients with Acute Lumbago Using a Single-Case Design. Journal of Physical Therapy Science, 26, 755-758. https://doi.org/10.1589/jpts.26.755

[18] Sairyo, K., Kawamura, T., Mase, Y., et al. (2013) Jack-Knife Stretching Promotes Flexibility of Tight Hamstrings after 4 Weeks: A Pilot Study. European Journal of Orthopaedic Surgery \& Traumatology, 23, 657-663. https://doi.org/10.1007/s00590-012-1044-6

[19] Raftry, S.M. and Marshall, P.W. (2012) Does a "Tight” Hamstring Predict Low Back Pain Reporting during Prolonged Standing? Journal of Electromyography and Kinesiology, 22, 407-411.

[20] Marshall, P.W., Cashman, A. and Cheema, B.S. (2011) A Randomized Controlled Trial for the Effect of Passive Stretching on Measures of Hamstring Extensibility, Passive Stiffness, Strength, and Stretch Tolerance. Journal of Science and Medicine in Sport, 14, 535-540.

[21] Shadmehr, A., Hadian, M.R., Naiemi, S.S. and Jalaie, S. (2009) Hamstring Flexibility 
in Young Women Following Passive Stretch and Muscle Energy Technique. Journal of Back and Musculoskeletal Rehabilitation, 22, 143-148. https://doi.org/10.3233/BMR-2009-0227

[22] Winters, M.V., Blake, C.G., Trost, J.S., et al. (2004) Passive versus Active Stretching of Hip Flexor Muscles in Subjects with Limited Hip Extension: A Randomized Clinical Trial. Physical Therapy, 84, 800-807.

[23] Kippers, V. and Parker, A.W. (1987) Toe-Touch Test. A Measure of Its Validity. Physical Therapy, 67, 1680-1684. https://doi.org/10.1093/ptj/67.11.1680

[24] Hasebe, K., Sairyo, K., Hada, Y., et al. (2014) Spino-Pelvic-Rhythm with forward Trunk Bending in Normal Subjects without Low Back Pain. European Journal of Orthopaedic Surgery \& Traumatology, 24, S193-S199.

https://doi.org/10.1007/s00590-013-1303-1

[25] Fasen, J.M., O'Connor, A.M., et al. (2009) A Randomized Controlled Trial of Hamstring Stretching: Comparison of Four Techniques. The Journal of Strength \& Conditioning Research, 23, 660-667. https://doi.org/10.1519/JSC.0b013e318198fbd1

[26] Halbertsma, J.P., van Bolhuis, A.I. and Göeken, L.N. (1996) Sport Stretching: Effect on Passive Muscle Stiffness of Short Hamstrings. Archives of Physical Medicine and Rehabilitation, 77, 688-692.

[27] Sjolie, A.N. (2004) Low-Back Pain in Adolescents Is Associated with Poor Hip Mobility and High Body Mass Index. Scandinavian Journal of Medicine \& Science in Sports, 14, 168-175. https://doi.org/10.1111/j.1600-0838.2003.00334.x

[28] Esola, M.A., McClure, P.W., Fitzgerald, G.K. and Siegler, S. (1996) Analysis of Lumbar Spine and Hip Motion during forward Bending in Subjects with and without a History of Low Back Pain. Spine, 21, 71-78. https://doi.org/10.1097/00007632-199601010-00017

[29] Hallman, D.M., Ekman, A.H. and Lyskov, E. (2014) Changes in Physical Activity and Heart Rate Variability in Chronic Neck-Shoulder Pain: Monitoring during Work and Leisure Time. International Archives of Occupational and Environmental Health, 87, 73-744. https://doi.org/10.1007/s00420-013-0917-2

[30] Sawada, T., Matsudaira, K., Muto, Y., Koga, T. and Takahashi, M. (2016) Potential Risk Factors for Onset of Severe Neck and Shoulder Discomfort in Urban Japanese Workers. Industrial Health, 54, 230-236. https://doi.org/10.2486/indhealth.2015-0143

[31] Matsudaira, K., Isomura, T., Miyoshi, K., Okazaki, H. and Konishi, H. (2014) Risk Factors for Low Back Pain: A New Concept. Nihon Rinsho, 72, 244-250. (In Japanese)

[32] Krantz, G., Forsman, M. and Lundberg, U. (2004) Consistency in Physiological Stress Responses and Electromyographic Activity during Induced Stress Exposure in Women and Men. Integrative Psychological and Behavioral Science, 39, 105-118. https://doi.org/10.1007/BF02734276 
Submit or recommend next manuscript to SCIRP and we will provide best service for you:

Accepting pre-submission inquiries through Email, Facebook, LinkedIn, Twitter, etc. A wide selection of journals (inclusive of 9 subjects, more than 200 journals)

Providing 24-hour high-quality service

User-friendly online submission system

Fair and swift peer-review system

Efficient typesetting and proofreading procedure

Display of the result of downloads and visits, as well as the number of cited articles Maximum dissemination of your research work

Submit your manuscript at: http://papersubmission.scirp.org/

Or contact health@scirp.org 